\title{
Who needs an endoscopic ultrasound?
}

\author{
Eric C Lam MD FRCPC
}

E ndoscopic ultrasound (EUS) is a technique that has seen increasing interest in the past decade. It has enabled the endosonographer to visualize details of anatomy and pathology not usually available to most gastroenterologists or even radiologists. The list of indications for EUS is growing and this has forced gastroenterologists to 'think outside the lumen' about the possibilities. Because EUS in Canada currently is limited to a few centres, EUS may not be foremost in the minds of gastroenterologists as a useful diagnostic and therapeutic tool.

Before outlining the evidence for the current indications for an EUS, it is important to understand what is available. Figure 1 shows the two scanning methods available. With radial EUS, the generated imaging plane is perpendicular to the long axis of the endoscope. This provides a $270^{\circ}$ or $360^{\circ}$ cross-sectional view of the mediastinum and rectum, and an overall view of the upper retroperitoneum. It is unsuitable for fine needle aspiration biopsy. With linear EUS, the imaging plane is generated in parallel to the long axis of the endoscope. Although this method provides a limited wedgeshaped scanning plane, the entire trajectory of a fine needle aspiration biopsy needle can be visualized and is therefore the method of choice to biopsy lesions.

Another radial scanning technique is the miniprobe. These miniprobes measure $2.5 \mathrm{~mm}$ in diameter and can be advanced down a standard gastroscope. They are generally higher frequency probes that provide more detailed circumferential images of the bowel wall layers but havelimited depth of penetration. They are ideal for intramural lesions of the gastrointestinal tract.

The combined ability to image the layers of the bowel wall and structures adjacent to it has resulted in a powerful tool that has influenced clinical decision making. Common indications for EUS are listed in Table 1. The nongastrointestinal indications, such as lung cancer staging, are not discussed in the present article.

\section{PANCREATIC DISEASE}

EUS is currently regarded as one of the most accurate modalities to image the pancreas $(1,2)$. Unlike transabdominal ultrasound, overlying bowel gas does not obscure imaging of the head of the pancreas. EUS is also less dependent on body habitus distortion because the distance from the probe to the organ is shorter than with transabdominal ultrasound. In addition, there are limits to the resolution of cross-sectional imaging where small lesions are often difficult to visualize. The spatial relationship of the pancreas to the stomach makes EUS the best noninvasive modality to investigate focal lesions of the pancreas.

The use of EUS in pancreatic cancer should be considered if tissue diagnosis is required to plan palliative chemotherapy, or if the results of crosssectional imaging modalities are negative but the suspicion for a malignancy remains high. The yield of brush cytology from endoscopic retrograde cholangiopancreatography in distal biliary strictures suffers from poor sensitivity, especially if the lesion has subsequently been found to be originating from the pancreas (3). EUS is a safer technique to biopsy pancreatic malignancies compared with radiologically guided percutaneous techniques. Although the refinements in modern cross-sectional imaging have improved identification of pancreatic cancers, lesions less than $10 \mathrm{~mm}$ are often unidentified on computed tomography (CT). EUS can readily identify these lesions and is a useful test when the suspicion of a malignant obstruction is high in the face of a 'normal' CT scan. Accurate staging of pancreatic cancer relies on a combination of cross-sectional imaging and EUS.

Cystic neoplastic lesions of the pancreas pose a diagnostic dilemma. Often discovered incidentally on abdominal imaging, the malignant potential of these lesions is uncertain. Although surgery is definitive, EUS with fine needle aspiration of cyst contents can aid in the decision making. It has been shown that the EUS appearance of a cystic neoplasm alone is unreliable; however, additional cyst fluid tumour markers and biochemistry can help differentiate neoplastic cystic disease from non-neoplastic cystic disease $(4,5)$. Within neoplastic cystic disease, cyst fluid analysis can also help stratify those cystic neoplasms that have significant malignant potential. In the past, cystic neoplasms of the pancreas were often followed with serial cross-sectional imaging. The refinements in EUS techniques allow for identification of those lesions that may require surgery.

There are emerging data on the utility of EUS in the investigation of idiopathic acute recurrent pancreatitis (6). EUS is useful in the identification of biliary sludge, chronic pancreatitis and small obstructing lesions in the pancreas. It also helps to further characterize ampullary lesions and pancreas divisum. Some authorities have advocated the investigation of the first episode of acute pancreatitis in patients older than 40 years of age (7). The risk of malignancy increases with age and a small lesion in the pancreas, which may be missed by cross-sectional imaging, can be detected by EUS. 


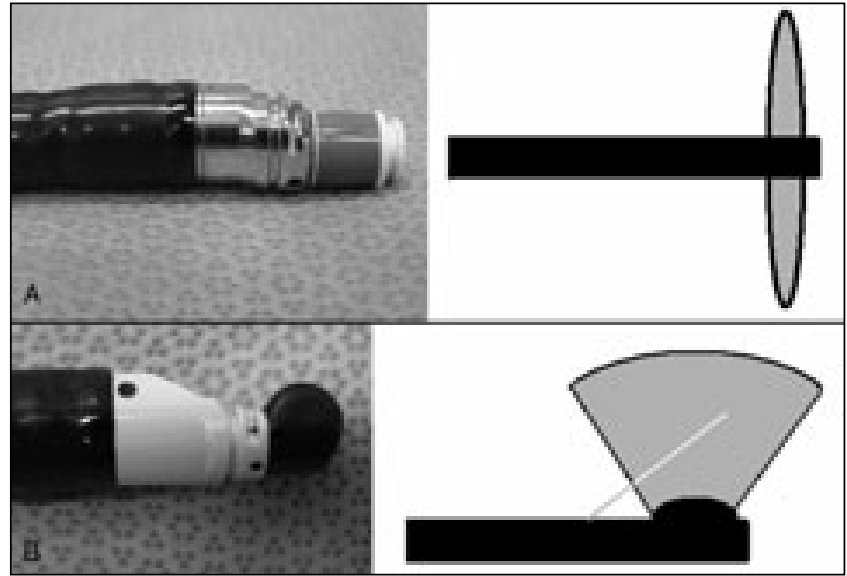

Figure 1) The two scanning methods in endoscopic ultrasound. A Radial; B Linear

More controversial is the role of EUS in the diagnosis of chronic pancreatitis. There is evidence to suggest that EUS can identify abnormalities in the parenchyma of the pancreas long before changes are seen on pancreatogram. A histological gold standard has yet to exist for chronic pancreatitis, but characteristic findings of parenchymal abnormalities on EUS have good agreement among expert endosonographers (8).

\section{STAGING OF LUMINAL MALIGNANCIES AND SUBEPITHELIAL LESIONS}

Use of high-frequency probes provide the endosonographer with the ability to visualize the layers of the gastrointestinal tract. After being identified by standard endoscopy, subepithelial lesions can be further characterized by both the echotexture of the lesion and the layer from which the lesion arises. Identifying the layer from which the lesion arises also provides information as to whether endoscopic biopsies are adequate, as in the case of hypertrophic gastridities. The differential diagnosis can be further refined in some cases with fine needle aspiration of locoregional structures. Although transabdominal ultrasound in expert centres can visualize intramural lesions within the stomach, EUS can characterize lesions not routinely accessible by transcutaneous ultrasound, such as esophageal and rectal lesions.

Detailed images of the layers of the gastrointestinal tract enable the endosonographer to stage tumours based on the TNM classification. Assessing the depth of luminal tumour penetration gives the gastroenterologist an indication as to whether endoscopic resection will be feasible and safe, whether there is associated locoregional lymph node enlargement and if there is evidence of tumour adherence to adjacent organs.

Numerous studies have investigated the staging accuracy of EUS in esophageal cancer (9). EUS has a T staging accuracy of $80 \%$ and is useful in documenting locoregional lymph nodes and metastatic disease to the celiac lymph nodes and left lobe of the liver. Because EUS cannot image the right lobe of the liver effectively, CT remains important in the staging of esophageal cancer. Therefore, EUS can help identify those patients who would benefit most from chemotherapy and surgery compared with those in which a palliative management strategy would be preferred.

EUS has a limited role in the staging of resectable gastric cancer. This is because the proper staging of gastric malignancies requires examination of all locoregional lymph nodes, some of
TABLE 1

Common disease indications for endoscopic ultrasound

\begin{tabular}{|c|c|c|}
\hline Indication & Condition & Comment \\
\hline \multirow{7}{*}{$\begin{array}{c}\text { Pancreatic } \\
\text { disease }\end{array}$} & Adenocarcinoma & FNA, staging \\
\hline & Cystic neoplasms & Staging, cyst fluid analysis \\
\hline & Metastatic disease & $\begin{array}{l}\text { Especially from renal cell } \\
\text { carcinoma }\end{array}$ \\
\hline & Chronic pancreatitis & \\
\hline & $\begin{array}{l}\text { Idiopathic acute } \\
\text { recurrent pancreatitis }\end{array}$ & $\begin{array}{l}\text { Intraductal papillary } \\
\text { mucinous neoplasm, } \\
\text { chronic pancreatitis, } \\
\text { pancreas divisum }\end{array}$ \\
\hline & Neuroendocrine tumours & \\
\hline & Pseudocyst & \\
\hline \multirow[t]{4}{*}{$\begin{array}{l}\text { Luminal wall } \\
\text { abnormalities }\end{array}$} & Adenocarcinoma & $\begin{array}{l}\text { Staging for esophagus, } \\
\text { occult gastric } \\
\text { metastases, rectal }\end{array}$ \\
\hline & Subepithelial neoplasms & $\begin{array}{l}\text { Carcinoid, GIST, } \\
\text { leiomyoma, } \\
\text { leiomyosarcoma }\end{array}$ \\
\hline & Thickened gastric folds & After endoscopic biopsies \\
\hline & $\begin{array}{l}\text { Confirm benign nature } \\
\text { of subepithelial lesion }\end{array}$ & $\begin{array}{l}\text { Lipomas, pancreatic rest, } \\
\text { pneumatosis }\end{array}$ \\
\hline \multirow[t]{2}{*}{ Biliary disease } & Choledocholithiasis & Including biliary sludge \\
\hline & Adenocarcinoma & $\begin{array}{l}\text { Cholangiocarcinoma, } \\
\text { gallbladder carcinoma }\end{array}$ \\
\hline Non-GI disease & Lung cancer & Mediastinal staging \\
\hline \multirow[t]{2}{*}{$\begin{array}{l}\text { Therapeutic } \\
\text { interventions }\end{array}$} & Pancreatic pseudocyst & $\begin{array}{l}\text { Drainage and } \\
\text { stent insertion }\end{array}$ \\
\hline & Celiac plexus neurolysis & Malignant pancreatic pain \\
\hline
\end{tabular}

FNA Fine needle aspiration; GI Gastrointestinal; GIST Gastrointestinal stromal tumour

which may not be well visualized by EUS. EUS, however, is primarily used to determine whether there is occult metastatic disease. Perigastric fluid in the setting of gastric cancer is worrisome for peritoneal carcinomatosis and this is readily identified by EUS. Furthermore, if there is adherence of tumour to adjacent organs, advanced stage disease can be identified.

\section{BENIGN BILIARY DISEASE}

As mentioned previously, EUS is useful in the detection of biliary sludge in the gallbladder as well as the common bile duct. Transabdominal ultrasound has low sensitivity for choledocholithiasis even in patients with a suggestive history.

EUS has a diagnostic accuracy of over $96 \%$ for choledocholithiasis (10). Intrahepatic biliary dilation and lesions at the bifurcation of the common hepatic duct are more difficult to image but the biliary tree can be followed by EUS down to the ampullary orifice. With a risk of pancreatitis less than $0.3 \%$, EUS is the imaging modality of choice in patients with a low or moderate probability of common bile duct stones (11). This can help stratify patients into risk groups that would benefit most from endoscopic retrograde cholangiopancreatography.

\section{THERAPEUTIC INTERVENTIONS}

The emerging interest in EUS is probably best illustrated by the therapeutic capabilities of this technology. Fine needle 
aspiration techniques have provided us with more information but have also guided development of therapeutic techniques.

The celiac plexus of nerves are found inferior and lateral to the celiac artery takeoff from the aorta. Pain fibres from the pancreas converge at this area. Malignant pain from pancreatic lesions at the genu and body of the pancreas has traditionally been treated by celiac plexus neurolyses performed under CT or fluoroscopic guidance. EUS can safely deliver the same treatment from the anterior approach through the fundus of the stomach and is better tolerated by the patient. Bilateral injection of absolute alcohol has been shown to be safe and effective (12). This offers good palliation of malignant pancreatic pain and limits use of narcotic medications.

Symptomatic pancreatic pseudocysts have been punctured blindly in the past. Regional varices, especially in the setting of splenic vein thrombosis after severe acute pancreatitis, are often seen on cross-sectional imaging. EUS is useful for identifying a site at which puncture of the pseudocyst is safe and away from these varices. Furthermore, the presence of loculations and debris within the cyst can be identified. Using the linear therapeutic EUS scope enables the endosonographer to insert stents to create a cystgastrostomy or cystduodenostomy.

\section{CONCLUSION}

EUS is a technique that provides information that influences clinical decisions. This minimally invasive test can help further characterize gastrointestinal lesions and stratify patients to additional risk appropriate testing and treatments. Its main uses are to evaluate subepithelial lesions, pancreatic disease and biliary disease; it is also used for staging luminal malignancies and to deliver safer therapeutic options in celiac plexus neurolysis and pancreatic pseudocyst drainage.

Although currently limited to a few Canadian centres, the future of EUS diagnosis and therapy is promising.

\section{REFERENCES}

1. Wiersema MJ. Accuracy of endoscopic ultrasound in diagnosing and staging pancreatic carcinoma. Pancreatology 2001;1:625-32

2. Anderson MA, Carpenter S, Thompson NW, et al. Endoscopic ultrasound is highly accurate and directs management in patients with neuroendocrine tumors of the pancreas. Am J Gastroenterol 2000;95:2271-7.

3. Rosch T, Hofrichter K, Frimberger E, et al. ERCP or EUS for tissue diagnosis of biliary strictures? A prospective comparative study. Gastrointest Endosc 2004;60:390-6.

4. Hammel P. Role of tumor markers in the diagnosis of cystic and intraductal neoplasms. Gastrointest Endosc Clin N Am 2002;12:791-801.

5. Brugge WR, Lewandrowski K, Lee-Lewandrowski E, et al. Diagnosis of pancreatic cystic neoplasms: A report of the cooperative pancreatic cyst study. Gastroenterology 2004;126:1330-6.

6. Yusoff IF, Raymond G, Sahai AV. A prospective comparison of the yield of EUS in primary vs recurrent idiopathic acute pancreatitis. Gastrointest Endosc 2004;60:673-8.

7. Choudari CP, Fogel EL, Sherman S, et al. Idiopathic pancreatitis: Yield of ERCP correlated with patient age. Am J Gastroenterol 1998;93:1654A. (Abst)

8. Wallace MB, Hawes RH, Durkalski V, et al. The reliability of EUS for the diagnosis of chronic pancreatitis: Interobserver agreement among experienced endosonographers. Gastrointest Endosc 2001;53:294-9.

9. May A, Gunter E, Roth F, et al. Accuracy of staging in early oesophageal cancer using high resolution endoscopy and high resolution endosonography: A comparative, prospective, and blinded trial. Gut 2004;53:634-40.

10. de Ledinghen V, Lecesne R, Raymond JM, et al. Diagnosis of choledocholithiasis: EUS or magnetic resonance cholangiography? A prospective controlled study. Gastrointest Endosc 1999;49:26-31.

11. Mortensen MB, Fristrup C, Holm FS, et al. Prospective evaluation of patient tolerability, satisfaction with patient information, and complications in endoscopic ultrasonography. Endoscopy 2005;37:146-53.

12. Lemelin V, Lam E, Sahai AV. A prospective trial of central versus bilateral celiac plexus block/neurolysis in 160 patients: Bilateral injection is safe and is more effective. Gastrointest Endosc 2005;61:AB77. (Abst) 


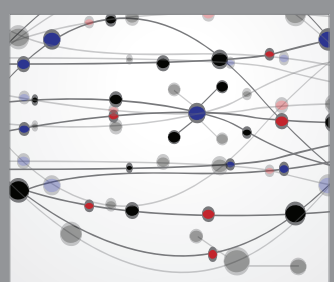

The Scientific World Journal
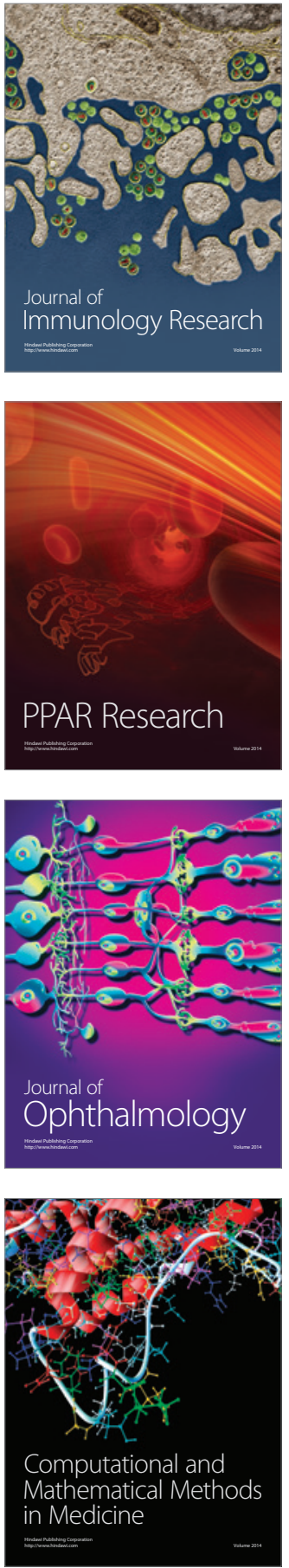

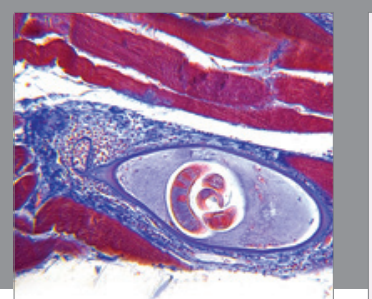

Gastroenterology Research and Practice

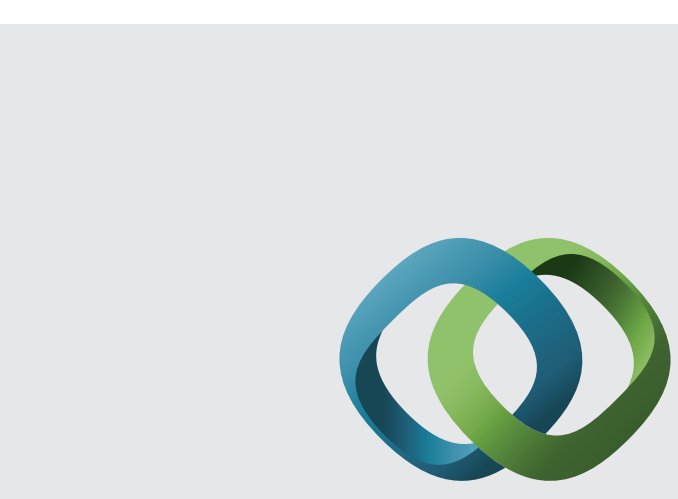

\section{Hindawi}

Submit your manuscripts at

http://www.hindawi.com
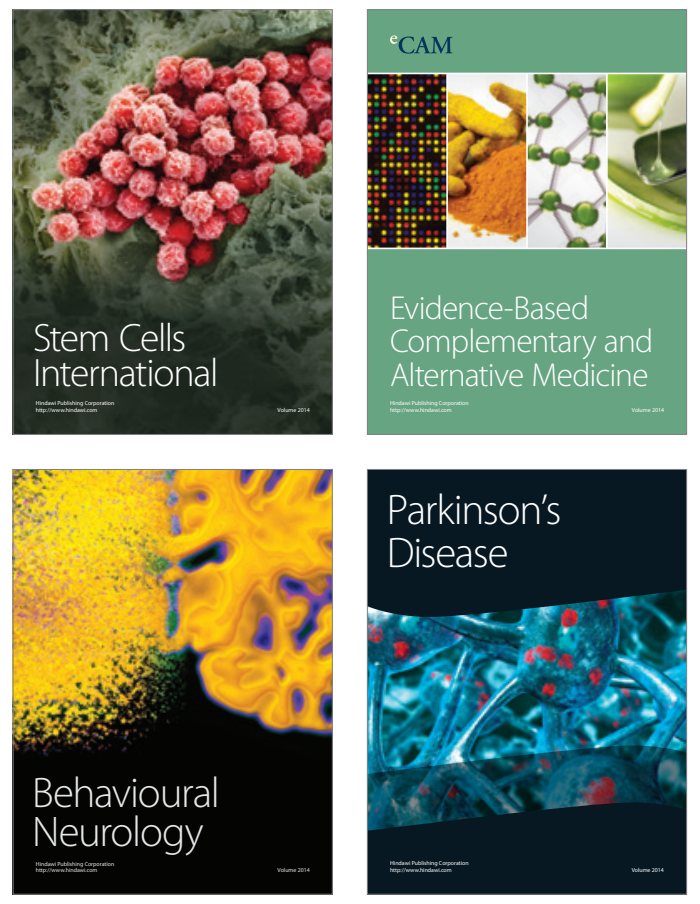
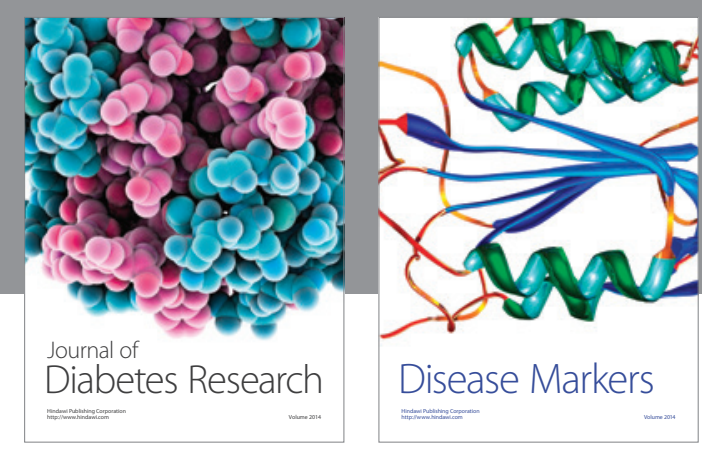

Disease Markers
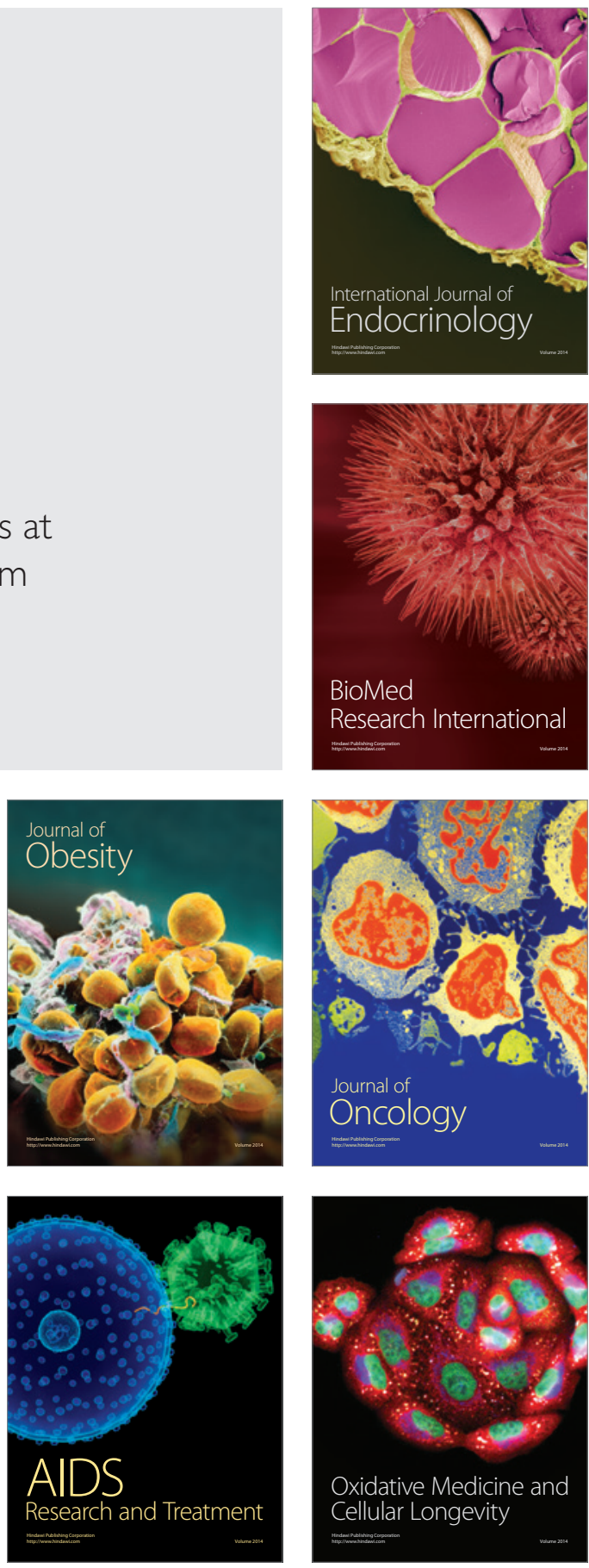